\title{
MEMÓRIA E HUMANIDADE CIBORGUE: BLADE RUNNER E A DICOTOMIA HUMANO MÁQUINA'
}

HAMILCAR SILVEIRA DANTAS JUNIOR

https:/ /orcid.org/0000-0003-4214-0629

Universidade Federal de Sergipe

FABIO ZOBOLI

https://orcid.org/0000-0001-5520-5773

Universidade Federal de Sergipe

RENATO IZIDORO DA SILVA

https:/ /orcid.org/0000-0002-0368-7384

Universidade Federal de Sergipe

RESUMO Este artigo objetiva interpelar a memória para discorrer sobre a dicotomia humano/máquina - ciborgue - no clássico Blade Runner (1982). Na diegese fílmica, a dúvida sobre a condição do protagonista Rick Deckard, humano ou replicante, é colocada como base a uma discussão acerca da memória como atributo de distinção entre o natural e o artificial, o humano e o replicante. Conclui-se que a figura do ciborgue na narrativa filmica sugere a superação de dualismos usados para explicar de modo esquemático nossa existência.

Palavras-chave: Ciborgue. Dicotomia humano/máquina. Filme Blade Runner. Memória.

\section{ABSTRACT CYBORG MEMORY AND HUMANITY: BLADE RUNNER AND THE HUMAN/MACHINE DICHOTOMY}

This article aims to challenge memory to discuss the human/machine - cyborg dichotomy in the classic Blade Runner (1982). In filmic diegesis, the doubt about the condition of the protagonist Rick Deckard, human or replicant, is placed as the basis for a discussion about memory as a distinguishing attribute between the natural and the artificial, the human, and the replicant. It is concluded that the cyborg figure in the film narrative suggests the overcoming of dualisms used to schematically explain our existence.

1 Este artigo foi apoiado com recursos do Programa de Pós-Graduação em Educação (PPGED) da Universidade Federal de Sergipe (UFS), do Programa de apoio ao Pesquisador à Pós-Graduação (Proap) e da Coordenação de Aperfeiçoamento de Pessoal de Nivel Superior (Capes). 
Keywords: Cyborg. Human/machine dichotomy. Movie Blade Runner. Memory.

\section{RESUMEN MEMORIA Y HUMANIDAD CYBORGUE: BLADE RUNNER Y LA DICOTOMÍA HUMANO/MÁQUINA}

Este artículo tiene como objetivo interpelar la memoria para discutir la dicotomía humano / máquina - cyborg - en el clásico Blade Runner (1982). En la diegesis fílmica, la duda sobre la condición del protagonista Rick Deckard, humano o replicante, se coloca como la base para una discusión sobre la memoria como un atributo distintivo entre lo natural y lo artificial, lo humano y lo replicante. Se concluye que la figura del cyborg en la narrativa de la película sugiere la superación de los dualismos utilizados para explicar de manera esquemática nuestra existencia.

Palabras clave: Cyborgue. Dicotomía humano/máquina. Película "Blade Runner". Memoria.

\section{Introdução}

Chegamos a 2019! Los Angeles continua uma típica metrópole dos Estados Unidos: grandes avenidas e trânsito caótico, população miscigenada, centros de compras, museus, praias e todas as referências à grande indústria do cinema, Hollywood, contrastando com a pobreza e suas tensões. No cinema, o musical La La Land (Damian Chazelle, Estados Unidos, 2016) narrou Los Angeles como uma cidade colorida, de sol radiante com um crepúsculo romântico, recheada de belos casais dançantes ao som de música pop. Mas, estamos em 2019, não era essa Los Angeles que o cinema previa há quase quatro décadas.

Em 1982, a Los Angeles projetada pelo diretor Ridley Scott, os roteiristas Hampton Fancher e David Peoples, inspirados na Londres de um conto de Philip K. Dick, possuiria carros voadores, viagens interplanetárias tripuladas, colônias espaciais e cyborgs tão perfeitos, tão assemelhados a humanos, que seria impossível identificar as diferenças, a não ser em testes específicos. O nivel de identidade com os humanos levou os cyborgs a reivindicarem estatuto de memória e experiência histórica, de sensibilidade humana. Esse é o futuro imaginado e representado em Blade Runner, o caçador de androides (Ridley Scott, Estados Unidos, 1982), produção da Warner Bros.

Nesse filme, uma Los Angeles caótica, governada por corporações, é habitada pelo “lixo humano", aquelas pessoas que não conseguem pagar para viver nas colônias espaciais. Nesse caos urbano, com uma chuva ácida permanente, a Tyrell Corporation fabricou replicantes/ ciborgues, seres semelhantes aos humanos em aparência, porém mais fortes e resistentes para executarem trabalhos pesados nas colônias. ${ }^{2}$ A série mais elaborada de replicantes, chamada de Nexus 6, é programada para viver

2 Aqui podemos pensar os replicantes como metáfora da manifestação de nosso desejo fundamental apontado por Baudrillard (1988), em sua obra O sistema dos objetos de que "tudo caminhe de forma autômata", que cada objeto, na função que the foi dada, cumpra o milagre da perfeição sem o menor esforço. Ainda nesse sentido, "muitas vezes, ciborgue é o escravo que executa as tarefas que não queremos assumir. Conceber uma criatura artificial como alter ego, é negligenciar que ela encarna pelo menos tanto a produção de escravos quanto a libertação de outros da sua servidão ao atender a todas as carências; é negligenciar a máquina-ferramenta que promete suprimir o trabalho" (HOQUET, 2019, p. 40). 
apenas quatro anos. O filme se inicia informando que quatro replicantes Nexus 6 chegaram à Terra. As informações são de que eles procurarão seu criador para adquirirem mais tempo de vida. Nesse momento, são acionados os Blade Runners, policiais responsáveis por "aposentar" (entenda-se exterminar) replicantes rebeldes. 0 mais famoso deles é convocado, Rick Deckard.

Blade Runner é um filme que tensiona dicotomias a fim de abalar certezas distintivas: humano/animal, humano/deus, natural/artificial, sujeito/objeto, animado/inanimado, humano/ máquina. Nesse tencionar de dicotomias, se conjugam dois processos: a escolha narrativa do diretor do filme - como se mostra e como nos é mostrado -; e a própria argumentação que sustenta a narrativa - o contar do enredo e das personagens. A construção dessas narrativas, que remontam a Platão e a Aristóteles, segundo Bordwell (1996, p. 4 e 16), possui duas teorias essenciais, respectivamente: a diegética e a mimética.

A teoria da narrativa mimética, dedicada por Aristóteles, alude aos meios, objetivos e modos de imitação do real; quais sejam, as figuras, as linguagens, os humanos e suas ações. Tais procedimentos se consubstanciam no ato de ver, no que se dá a ver e no mostrar ao espectador que, em maior ou menor grau, interage com o visto/mostrado acerca de um referente. 0 mundo é, então, reproduzido e mimetizado como similar ao real por meio de uma exposição ou mostra espetacular, cuja principal manifestação aristotélica é o teatro, mas também presente na pintura e na escultura da época, ao passo que, modernamente, temos, além da continuidade dessas, a emergência da fotografia, do cinema e da televisão. Para Platão, o poeta mimético narra mediante seus personagens postos em cenas no drama (BORDWELL, 1996, p. 16) narrado no presente sincrônico ao dos espectadores.
A teoria diegética, mais íntima da tradição platônica das exposições orais e escritas, que remonta à poesia antiga de Homero, considera o papel do poeta ou do filósofo na exposição ou dissertação de uma sequência de cenas, não utilizando das ações de outros para concatenar a história. Tende a se referir mais ao mundo fictício da história principalmente porque a palavra é signo "não idêntico" ou representado; ficando a cargo de quem escuta ou lê a produção mimética da cena em sua imaginação. A ficção, doravante, ocorre por duas vias: a da metalinguagem, que cria uma hierarquia de discursos e adapta empiricamente a realidade à narrativa; e da enunciação, uma atividade social na qual a comunicação é posta em movimento pela narração. Esse movimento busca conciliar quem enuncia a quem se dirige, como e quando se dirige o enunciado.

A diacronia da narrativa contada coloca o problema da sequência temporal "anteroposterior" dos acontecimentos de maneira mais evidente; enquanto na mimese, a sincronia entre mostrar e ver parece estar conciliada. A imitação também impõe uma conciliação entre a representação e a "espectativa", enquanto a dissemelhança da palavra com a coisa apresenta maiores dificuldades para produzir essa conciliação. O cinema herdou essa problemática entre mimese e diegese de maneira complexa justamente por operar simultaneamente por ambas as formas. Ora a sétima arte se aproximou e explorou mais o poder diegético da narrativa, ora se amparou na potência imitativa da imagem. Contudo, as aproximações entre cinema e literatura são mais comuns, principalmente, pelo número de obras transpostas reciprocamente de um ambiente para outro. Pouco circula os vínculos cinema/pintura, como detalha Aumont (2004), em O olho interminável: cinema e pintura.

A narrativa de Blade Runner, herdeira fracassada da tradição hollywoodiana clássica 
das obras de "grande público", experimenta as dificuldades impostas pela dialética mimese/ diegese; que pode ser interpretada pelo desafio do cinema da época em, ao mesmo tempo, ser uma obra visual e discursiva. Em outras palavras, os desafios de conciliar o espetáculo pictórico (fotográfico) com o literário; deixando a seguinte questão: seu fracasso de bilheteria pode ser justificado pelo estranhamento fotográfico ou romanesco provocado no público? Certamente o ambiente distópico intensifica o estatuto ficcional da obra, ao mesmo tempo que as imagens futuristas exigem do romance, e vice-versa, maior trabalho de conciliação ou de justificação semântica “imagem e texto".

A familiar relação heterossexual - Deckard e Rachael - romanesca, tencionada por uma trama detetivesca, supera a dicotomia mimese/diegese, pois constrói uma trajetória que enuncia essas tensões, projeta uma estranha distopia que mimetiza uma realidade e suas problemáticas inexistentes no real, mas existentes no plano metafórico e projetivo acerca do desenvolvimento pessimista e trágico da modernidade. 0 filme vincula a forma narrativa às intenções de suas personagens, cujo discorrer da história apresenta um "protagonismo fracassado", pois existe uma força maior, a do sistema, que se impõe aos destinos, de modo que o ato heroico parece se acovardar. o mimético apresenta e representa imagens ou ícones da distopia, mas é contado no sentido de uma sintaxe, uma sequência diegética em que passado e presente dialogam mediante um espaço de memória também fracassado, justamente por estar apoiado na narrativa suposta e artificialmente implantada em suas mentes.

Esse elemento é factível na medida em que a histórica ação mimética da ciência é exposta no filme em toda sua virulência. Historicamente, a ciência mimetiza a natureza e recria no mundo humano o que a natureza não nos concede: capacidade de voar, de navegar no fundo do oceano, de vencer vírus e bactérias agressivos, de construir mecanismos artificiais para ampliar nosso raio de ação, entre outros. Na diegese filmica, percebemos o quanto as grandes corporações sugaram a natureza através de guerras, destruição dos recursos de flora e fauna, legando-nos radiação e um ambiente inóspito à vida. Como alternativa, a Tyrel Corporation passa a mimetizar a Terra em colônias interplanetárias a ser habitadas por privilegiados sociais que são servidos pelo mimético orgânico de um novo trabalho escravo, os replicantes.

A narrativa filmica de Blade Runner, portanto, reproduz tanto os desafios tecnológicos do próprio cinema como mimese quanto sua diegese conta a história da ciência moderna em sua tarefa de mimetizar a natureza. Nesse processo de construção narrativa, o diretor Ridley Scott cria uma estética da "dúvida", usando muito bem o foco e o quadro do filme a fim de diluir as assertivas da condição identitária dos androides com os humanos, mimetizando-os com animais, objetos, seres inanimados e entornos do ambiente. Na película, "os seres artificiais se mimetizam, por sua vez, com os biológicos, de um modo quase completo" ${ }^{3}$ (SARTI, 2012, p. 242, tradução nossa). Essa falta de certeza quanto à humanidade dos androides se evidencia "também no tratamento das figuras, sempre diluídas, indiscerniveis, dentro das molduras"4 (SARTI, 2012, p. 243, tradução nossa).

A dúvida sobre o estatuto existencial androide é um dos eixos sob o qual gira a trama fílmica. Podemos deduzir isso na medida em que a diegese filmica se dá em torno da dúvida sobre a condição do protagonista Rick Deckard - o policial que foi destinado para matar os re-

3 "los seres artificiales se mimetizan, a su vez, con los biológicos, de un modo casi completo".

4 "también en el tratamiento de las figuras, siempre diluidas, indiscernibles, dentro de los encuadres". 
plicantes rebeldes: Rick Deckard é um humano? Ou seria ele também um androide? Para criar e tensionar a condição existencial de Deckard, Scott opta pela "memória" como característica de distinção entre humano e máquina (ciborgue). Na trama, Scott coloca nos replicantes ciborgues/androides - memórias de infância, lembranças de família, ou seja, ninguém pode ter certeza se Deckard é um ciborgue ou um ser humano exatamente por ele possuir essas memórias.

O que constitui um ser humano está na soma de suas memórias, na sua memória pessoal; mas, essa ainda pode ser artificial, não pode haver um terreno firme sobre o qual pensar. Portanto, Deckerd irá contemplar as fotos de seu próprio passado duvidando de sua autenticidade. 0 malvado gênio cartesiano, desta vez foi longe demais. ${ }^{5}$ (SARTI, 2012, p. 243, tradução nossa)

Frente ao exposto, o presente texto objetiva interpelar a memória para discorrer sobre a dicotomia humano/máquina a partir da narrativa filmica de Blade Runner: o caçador de androides. Partimos do pressuposto, conforme Alves (2006), de que Blade Runner é uma odisseia de homens e mulheres, humanos e pós-humanos em busca de sua identidade perdida; uma reflexão acerca dos limites entre identidade e memória como centralidade da existência humana. Tais limites expostos às fraturas sociais posto que vividos em um ambiente no qual a identidade humana é precarizada pelo desenvolvimento técnico-científico e pela engenharia genética, a dimensão técnica complexa de objetos e humanos desencantam a própria definição humana pela identificação dos seres a uma memória (passado/história). 0 escrito não pretende trazer respostas, ape-

5 "Lo que constiuye a un ser humano está en la suma de sus recuerdos, en la memoria personal; pero, si aún esta puede ser artificial, no puede haber suelo firme donde pensarse. Por tanto, Deckerd contemplará las fotos de su proprio pasado dudando de su autenticidad. El genio maligno cartesiano, esta vez ha ido demasiado lejos". nas suspender a problemática para pensar a dicotomia natural/artificial tão "replicante" na modernidade para tratar os limites da humanidade. Para tal, parte do conceito de ciborgue, ${ }^{6}$ como uma forma de "andrógino" que coagula dois opostos, apreendemos "uma criação vacilante, que surge em uma estrutura e a perturba por causa de sua necessária inadequação e inadaptação" (HOQUET, 2019, p. 47).

Com base no objetivo proposto, organizamos o texto a partir da seguinte pauta: num primeiro momento expomos a trajetória do filme Blade Runner como um amálgama de retalhos para ganhar vida; na sequência, discutimos a questão da memória como condição de identidade humana, incidindo sobre os limites entre natural e artificial ao considerarmos a iminência de uma humanidade ciborgue, já que esses são passiveis de uma construção histórica fundada na memória e não exatamente em fatos.

\section{Blade Runner: um filme feito de retalhos}

A menção a Blade Runner como um filme feito de retalhos é proposital para tecermos um paralelo com outra obra que também nos remete a litígios da dicotomia natural/artificial; a obra de Mary Shelley: Frankenstein. A odisseia narrativa de Blade Runner, recheada de montagens e remontagens, até ganhar sua última versão, é bastante similar à trajetória de publicação da obra de Mary Shelley, Frankenstein ou o Prometeu moderno. Segundo Guimarães (2018), com receio de assumir sua autoria, o

6 “Ciborgue é uma palavra-valise, composta para descrever uma realidade que não é menos realidade: o acoplamento entre uma forma artificial e uma forma natural, entre dois modos de regulação - uma máquina cibernética e um organismo. A palavra 'cibernética' foi cunhada por Norbert Wiener (1894-1964), a partir do grego kubernétès, o piloto, aquele que sabe a arte de conduzir um navio. A cibernética designa a "ciência do controle e da comunicação nos seres humanos e nas máquinas' e se interessa pela transformação da informação e pelo controle da ação" (HOQUET, 2019, p. 33). 
livro é publicado em janeiro de 1818, em três volumes, sem autoria, com prefácio de Percy B. Shelley e dedicado a William Godwin.? Em 1823, após assistir a uma encenação teatral da história criada por sua filha, Godwin lança uma segunda edição de Frankenstein, agora em dois volumes, mas ainda sem indicar a autora do romance. Finalmente, após trabalhar anos na sua organização, em 1831, é publicada a terceira edição de Frankenstein, a versão definitiva, dessa feita, assinada por Mary Shelley. Essa versão recebe um prólogo que introduz a narrativa, enfatiza-se a caracterização burguesa da família Frankenstein e a opressão às mulheres, sobretudo se constrói uma visão mecanicista da natureza, comandada por uma força amoral e inconsciente.

O retalho não é só metáfora da constituição da obra de Mary, mas também do nascimento da personagem central de seu romance: o monstro de Frankenstein. A novela de Shelley descreve a estória de Victor Frankenstein, um estudante de ciências naturais que constrói uma criatura com retalhos de corpos mortos, retirados das tumbas de um cemitério. Em seu laboratório, victor dá forma à criatura, costurando as partes desses corpos que, ao final, é animada - ganha vida - pela aplicação de "uma centelha de vida na coisa inerte" (SHELLEY, 2018, p. 65).

Sob a translação do retalho podemos pensar o filme Blade Runner. Os anos 1960, com sua efervescência cultural, lutas pelos direitos civis, movimento de trabalhadores, de contracultura, de minorias, de reflexões existenciais e humanistas, assistiu, no cinema, a uma guinada dos filmes de ficção científica que apontavam para horizontes distópicos desesperadores. Cineastas como Jean-Luc Godard, François Truffaut, Stanley Kubrick, Andrei Tarkovski, Michael Crichton, John Boorman e Norman Jewi-

7 Percy Bysse Shelley foi um poeta britânico, esposo de Mary Shelley; e William Godwin, escritor anarquista, era pai da escritora. son ${ }^{8}$ estabeleceram uma nova roupagem para o gênero, tensionando com os desdobramentos político-culturais e sinalizando com perspectivas alvissareiras na arte cinematográfica.

Não obstante, os anos 1970, ainda que com a ação dos cineastas da Nova Hollywood e sua afronta ao establishment dos estúdios, foi soterrada por uma nova perspectiva industrial: os blockbusters. Segundo Biskind (2009), após o sucesso de Tubarão (Steven Spielberg, Estados Unidos, 1975), a explosão de bilheteria de uma aventura espacial, pautada em uma narrativa simples e maniqueísta de luta entre o bem e o mal denominada Star Wars (George Lucas, Estados Unidos, 1977), retomou o cinema industrial e moldou o cinema de aventura com moldes de ficção científica para as próximas décadas. Com esse sucesso, abordar ficção científica por um prisma reflexivo não estava mais nos planos dos grandes estúdios.

Segundo Beck (2018), ainda sob a influência dos anos 1960 e as reflexões no campo da ficção científica, o roteirista Hampton Fancher resolve investir em uma história de Philip K. Dick, publicada em 1968, chamada Do androids dreams of electric sheep? Entre disputas com o escritor da obra original, os produtores de Hollywood e o chamado para a direção, Ridley Scott, a conclusão do roteiro leva 10 anos, sendo reescrito até chegar à forma definitiva proposta por Scott e o novo roteirista David Peoples. Uma história mais ácida pautava uma narrativa lenta, reflexiva acerca da condição humana diante dos horizontes futuristas desesperançados e caóticos.

8 Alphaville (Alphaville). Direção: Jean-Luc Godard. França, 1965; Fahrenheit 451 (Fahrenheit 451), Direção: François Truffaut. França, 1966; 2001: uma odisseia no espaço (2001: a space odissey). Direção: Stanley Kubrick. Inglaterra, 1968; Solaris (Solyaris). Direção: Andrey Tarkovski. União Soviética, 1972; Westworld, onde ninguém tem alma (Westworld). Direção: Michael Crichton. Estados Unidos, 1973; Zardoz (Zardoz). Direção: John Boorman. Inglaterra, 1974; Rollerball, os gladiadores do futuro (Rollerball). Direção: Norman Jewison. Estados Unidos, 1975. 
Uma primeira grande tensão é na escoIha do elenco. Para o personagem principal, o caçador de replicantes Rick Deckard, foi contratado o ator Harrison Ford. A intenção era aproveitar o sucesso do ator em dois blockbusters recentes: Star Wars, na pele do mercenário Han Solo, e Caçadores da arca perdida (Steven Spielberg, Estados Unidos, 1981), como o arqueólogo aventureiro Indiana Jones. Contudo, o personagem Deckard era o oposto do modelo que se construiu dele, pois era um anti-herói que atirava em mulheres pelas costas, ao tempo que era agredido por replicantes, apesar de ter sido salvo, em dois momentos-chave da história, por dois replicantes (Rachael e Roy).

Concluida a película, o filme original sofreu críticas nas exibições-teste e passou por uma nova montagem. A ação final do produtor Michael Deeley impôs os seguintes recursos narrativos: uma narração em off que buscava explicar todo o filme para o espectador; 9 colocou um final idílico em cenário verdejantes com a fuga de Rachael e Deckard; além de suprimir duas cenas-chave, uma em que Deckard sonhava com um unicórnio e outra que recebia, ao final do filme, um origami de unicórnio. Essas cenas indicavam a possibilidade de que o próprio Deckard seria um replicante. Com Harrison Ford fora do seu padrão-personagem consagrado, com a estreia de vários concorrentes de peso, sobretudo, ET: o extraterrestre

9 A narração em off, inserida por Michael Deeley e sempre rejeitada por Ridley Scott, reflete, segundo Bordwell (1996), uma estratégia de narrativa filmica diegética como metalinguagem. Nesse procedimento, a personagem fala e seu discurso é estruturado por seu equivalente metalinguístico: a câmera. Ela nos fala, a câmera nos mostra e, assim, ela (personagem) nos conduz. As opções de Ridley Scott nunca foram de nos conduzir, mas nos empurrar no turbilhão de dúvidas do próprio Deckard. Diante de seres tão perfeito, tão mimetizados, capazes de serem identificados somente por um processo (o teste Voight-Kampff) que não é infalivel, quem é humano? Essa fronteira ainda existe? O sonho de mimetizar o humano, ao ponto de desconfiar de sua própria condição de humano, é uma realidade para Deckard ou ainda um sonho de Tyrell?
(Steven Spielberg, Estados Unidos, 1982); Blade Runner se tornou um fracasso retumbante de bilheteria.

Em contrapartida, Blade Runner torna-se um sucesso na Europa, que valorizou a estética noir, as lacunas que produziam reflexões, as relações com o expressionismo alemão e a literatura/cinematografia distópica: representações do niilismo, do vazio, da ausência de valores e sentido para a vida/sociedade capitalista. Torna-se um cult movie, após seu lançamento em VHS (fitas de videocassete), mas principalmente com a circulação em um festival mediante uma cópia de $70 \mathrm{~mm}$ e com a pretensa versão original de Ridley Scott (BECK, 2018). Essa recepção de sucesso fez com que a Warner Bros lançasse, em 1992, a Versão do diretor (ainda que não realizada por Ridley Scott, e sim por Les Healey, assistente de edição da obra original): essa versão suprimia a narração em off, o final feliz e restituía o sonho do unicórnio. Porém persistiam os problemas de continuidade, de sincronia e de efeitos visuais.

Ainda insatisfeito com essa versão, Scott dedica-se, desde 2001, a produzir o seu final cut, que é lançado com sucesso em 2007. Essa é considerada a síntese definitiva do diretor. Todavia, a saga desse universo distópico não se concluiria aqui. Sob a supervisão de Scott, a Warner lança em 2017, pela internet, três curtas que explicariam os fatos ocorridos após o final do filme, de modo a preparar os fãs para o filme Blade Runner 2049 (Dennis Villeneuve, Estados Unidos, 2017). A trajetória desse filme demonstra que Ridley Scott foi um artesão da vida que, por meio de seus retalhos cinematográficos, construiu personagens humanos e maquínicos em um filme que ainda provoca reflexões sobre a existência; reflexões ainda necessárias e em processo, principalmente, considerando as nossas agruras quanto à finitude da vida e como se configuram nossas vidas ante a construção de memórias - lembran- 
ças e esquecimentos - produzidas ao longo da existência; agora em um mundo fabricado por registros e arquivos tecnológicos audiovisuais.

As trajetórias das obras citadas - literária e cinematográfica -, dos seus construtores artísticos - Shelley e Scott -, dos seus personagens cientistas - Victor Frankenstein e Eldon Tyrell e das suas criações - criatura de Frankenstein e replicantes -, aproximam-se não só pelos retalhos, mas também por suas poéticas narrativas que questionam a relação do humano com a ciência no que tange aos auspícios da técnica, que borram os limites do humano na sua fusão com o tecnológico maquínico - codinome do artificial. Como a memória pode ser pensada a partir das relações humanas com o artificial tecnológico com os quais se relaciona? Como Blade Runner tensiona a memória na dicotomia humano/máquina?

\section{Memória e humanidade ciborgue em Blade Runner}

Na Versão do Diretor, assistimos à cena em que Deckard está em casa, após matar uma replicante, triste ao piano, e tem um estranho sonho com um unicórnio correndo por uma floresta de contos de fadas. Tal cena nada significaria até o final do filme quando vai buscar Rachael para fugir, pois seu parceiro Blade Runner Gaff vai matá-la. Ao chegar ao apartamento, Deckard encontra um pequeno origami de unicórnio. Ao longo de todo filme, vemos Gaff fazer origamis variados. Aquele pequeno unicórnio pode indicar que Gaff tem acesso às memórias de Deckard sinalizando, então, que este também é um replicante de memórias fabricadas. Agora, a fuga é ainda mais imperativa: o filme termina com Deckard e Rachael fechando a porta de um elevador e entrando nas sombras. Esse final em aberto nos deixa perplexos diante dessas possibilidades: Deckard e Rachael não tinham o dispositivo de redução do tempo de vida? Se as memórias são implantadas, como os sentimentos afloraram entre os dois a ponto de se descobrirem apaixonados? Como é possivel que os replicantes tenham memória? Estaria, então, na imaginação e na memória a capacidade de demarcação do que é humano?

Para Pourriol (2009), seria uma contradição dessa cena mostrar um replicante, um ser não real, não natural, imaginando/sonhando com outro ser irreal, o unicórnio. 0 replicante seria em si, o unicórnio que existe! Divergimos acerca da contradição, visto que a narrativa estabelece a referência onírica ao unicórnio como elemento distintivo dos androides em face dos humanos; definindo uma relação de identidade entre um objeto por muitos considerado o imaginário por excelência, utilizado como exemplo por diferentes filósofos da tradição ocidental para diferenciar real de irreal, dentre os quais o empirista David Hume; e um objeto - o androide - cuja existência é duvidosa.

Entretanto, o unicórnio é historicamente uma criação da imaginação humana que, aliás, é perpetuada como parte da história de nossas ideias; que no filme o programador de ciborgues implantou na imaginação deles para negar a existência corporal em favor de uma (in)existência virtual e simbólica. Não seria esse um modo de levar os androides se convencerem da própria (in)existência imaginária, já que "imaginar é formular a existência"? Haveria, ainda, alguma referência filmica ao conceito de desejo em psicanálise, visto que o unicórnio é ícone e símbolo do mundo fantástico do neurótico, ao lado de fadas e duendes? Nesse caso, se confirmaria a própria existência androide como sujeito de desejo e de potência e, portanto, humano?

Imaginar é formular a existência. Os escrúpulos de Deckard em eliminar seres vivos injustamente considerados fictícios, exprimem-se e encontram uma compensação quando ele se propor- 
ciona a satisfação de dar vida a uma criatura imaginária. Se imaginar é afirmar a existência, a imaginação é uma potência de vida, a imaginação afirma a vida. (POURRIOL, 2009, p. 207)

Em Blade Runner, as memórias estão por toda parte, não apenas pelas narrativas contadas, mas pelos registros e vestígios visuais: as fotografias de Rachael e Deckard estão expostas dando a certeza de suas histórias, vivências e experiências humanas. Nesse ponto, chama a atenção o fato de a imagem técnica - a fotografia -, isto é, uma “imagem máquina", produzida por um aparelho não humano, ser designada como signo de humanidade. Por que a referência onírica do unicórnio, como produção humana por excelência - desde que ignoremos se os animais e plantas sonham -, fora eleita para referenciar a identidade androide, enquanto a "imagem tecnológica" da máquina fotográfica fora designada para significar a existência humana?

A questão parece não estar no ato fotográfico, mas sim em seu conteúdo, já que androides poderiam ser fotografados. É a infância registrada na fotografia que significa a humanidade, dizendo que o estado atual adulto ou civilizado dependeu de um desenvolvimento, de mudanças, desdobramentos, metamorfoses. Mais especificamente, a fotografia da infância deve envolver experiências humanas familiares, dado que na fotografia carregada/abandonada por Rachael temos uma mulher e uma menina, possivelmente mãe e filha, sentadas na entrada/escada de uma casa de madeira, aparentemente uma "casa de campo" ligada a vivências junto à natureza. Por isso, Deckard, convencido de que Rachael é replicante, exige dessa última memórias ligadas ao humano "natural": mãe, irmão, aranha, arbusto, ovos, verão etc.

Esse ambiente demandado por Deckard para sustentar a identidade de Rachael com a fotografia também nos remete ao bosque - natureza - por onde o unicórnio cavalga nos so- nhos do caçador de androides. Há uma identidade entre o sonho com o unicórnio (prova da existência androide) produzido por Deckard (supostamente humano) e a fotografia (prova da existência humana) portada por Rachael. Essa identidade é o ambiente de campo, de natureza: mãe/filha (procriação); cavalo/árvore (selvagem). Se o primeiro é humano, não poderia sonhar com unicórnio, ao passo que, se a segunda é uma androide, não poderia portar uma fotografia de infância. Não podemos ainda perder de vista que a figura do unicórnio está diretamente ligada à infância: somente crianças, ou ao menos pessoas que passaram pela infância, podem crer na existência de unicórnios e fadas mesmo restritos ao imaginário.

A narrativa promove um verdadeiro curtocircuito nos limites entre natural/artificial; humano/androide. Depois do teste a que Rachael fora submetida, descobre-se que ela é uma replicante: a identidade do ser é confirmada pelo instrumento técno-científico. Mas, e as memórias? Sendo implantadas, não vividas, Rachael deixa de ser humana? E as experiências adquiridas após sua criação agora a tornam humana? Em que medida, as experiências vivenciadas por Roy e os replicantes que lidera, os torna humanos? Será que a raiz crítica de Blade Runner não tem a intenção de dizer que, na verdade, os replicantes são os verdadeiros humanos justamente por sonharem com unicórnios (expressão máxima da fantasia como estatuto da humanidade que passa por uma infância); mas que tentam ser convencidos pelos verdadeiros androides de que não são humanos, inclusive apagando lembranças?

Afirma-se mais uma vez a metáfora cinematográfica de que as máquinas passaram a dominar os humanos e a base desse domínio evoca o controle das imagens? Ou a fotografia como signo de humanidade quer dizer que o humano é filho da técnica, como conta o mito de Prometeu e seu prolongamento no roman- 
ce de Shelley? Na medida em que a memória é um implante, também se pode convencer um humano de sua existência androide. A memória pode parecer a princípio individual, como se um conjunto de processamentos psíquicos acessasse um banco de dados e informações arquivadas das nossas experiências vividas. Todavia, conforme Halbwachs (1990), a memória é um fenômeno coletivo e social, submetido às tensões, deslizes, transformações e intencionalidades das coletividades humanas em relações. Nossa identidade humana com a memória depende, necessariamente, da narrativa que nossos familiares ou nossos historiadores implantam em nossa mente.

O fato incontornável parece ser o de não podermos estabelecer um contato ou experiência direta com nossa origem, de modo que prevalecem as imagens fragmentadas; sem contexto, sempre permeadas por realidades oníricas e delirantes. Diante dessa definição de memória, a construção da identidade dos sujeitos se dá na mediação de experiências vividas coletivamente, incluindo, na modernidade, nossas máquinas; especialmente a máquina fotográfica e, hoje, o smartphone. Segundo Pollak (1992), a memória coletiva e social se dá por três vias: os acontecimentos vividos pessoalmente e pelo grupo ao qual pertencemos; pelas pessoas e personagens com as quais convivemos ou, em algum momento travamos contato, pessoal ou por meios diversos (leituras, imagens, conversas); e pelos lugares que experimentamos ou sonhamos experimentar.

Se compreendermos as experiências vividas ou acumuladas em nossa psique, não haveria fronteiras entre memórias vividas (humanos) ou implantadas (replicantes). Não obstante há um outro elemento agravante a essa tensão: a dimensão da identidade. Segundo Pollak (1992, p. 204), a identidade

[...] é o sentido da imagem de si, para si e para o que outro é, a imagem que uma pessoa adquire ao longo da vida referente a ela própria, a imagem que ela constrói e apresenta aos outros e a si própria, para acreditar na sua própria representação, mas também para ser percebida da maneira como quer ser percebida pelos outros.

Esse sentimento de identidade se ampara em três elementos essenciais: a unidade física do indivíduo, ou as fronteiras físicas do seu corpo em relação a si e ao grupo de convívio; a continuidade dentro do seu tempo vivido; e o sentimento de coerência, visto que os elementos que fazem o indivíduo singular também o unificam em seu entorno social. A memória é, por conseguinte, o elemento constitutivo do sentimento de identidade. Por isso, os replicantes buscam tempo de vida, buscam mais tempo para ampliar suas memórias, já que, se são implantadas não são menos sentidas e experimentadas individualmente. Se a base de nossa humanidade é a identidade humana e nossa capacidade de rememorar, acumular experiências e resgatá-las, o desejo dos Nexus 6 é plenamente legítimo e, talvez, seja o limiar do que os possa configurar como humanos! Principalmente pela identidade entre fantasia e desejo depois das descobertas freudianas.

$\mathrm{Na}$ casa de J. F. Sebastian, o humano que fabrica as partes orgânicas que comporão novos replicantes, Pris, a replicante namorada de Roy, avisa: "Não somos computadores! Penso, Sebastian, logo existo!" (Blade Runner, 1982). Tal alusão, tão direta à máxima de Descartes, liga-se diretamente às motivações dos replicantes liderados por Roy, buscar mais vida, mais experiências, mais acúmulos de memória. Nesse sentido, a máxima cartesiana está amparada na ideia humana de que, se o entendimento é finito, a vontade dele é infinita. Quando o entendimento não me possibilita resoluções, cabe à vontade buscá-las. Para Descartes (2001), a máxima das ações estaria na firmeza e resolução em seguir em frente, seguindo as opções sob suspeição, mas expondo 
-as com firmeza e segurança; algo que expõe o lado romântico do racionalismo cartesiano: o humano se definir pela expressão da vontade humana, que no Romantismo Alemão não está separada da "vontade de natureza".

Mas, não basta apenas a vontade, o desejo, quatro anos de vida é pouco tempo para alcançar a plenitude da humanidade com acúmulo de memórias. Está posta aqui a intenção fundante da Tyrel Corporation, a manipulação da memória através de um implante de experiências imaginadas é a base do controle social proposto pela empresa. Em diálogo com Deckard, Tyrel afirma: “eles são emocionalmente inexperientes, têm poucos anos para coletar experiências que nós achamos corriqueiras. Fornecendo a eles um passado criamos um amortecedor para sua emoção e os controlamos melhor" (Blade Runner, 1982). Esse controle social limitaria, então, os replicantes a memórias individuais, meras próteses de experiência, portanto, eles não seriam humanos, pois não teriam memória coletiva! Mas como Roy e Pris estabelecem uma relação amorosa? Como Roy se incomoda tanto com a "aposentadoria" (extermínio) de Zora por parte de Deckard? Em que momento se constituíram essas memórias coletivas?

Essa busca por se afirmarem como seres de existência, seres de memória, seres de identidade com uma história, e que culmina no embate entre Deckard e Roy, alcança seu brilhante final no solilóquio proferido por Roy após salvar a vida de Deckard: "Eu vi coisas que vocês não imaginariam. Naves de ataque em chamas ao Largo de Órion. Eu vi Raios-C brilharem na escuridão próximos ao Portal de Tannhäuser. Todos esses momentos se perderão no tempo, como lágrimas na chuva. Hora de morrer" (Blade Runner, 1982). A criatura, ao salvar o "humano" e evocar suas memórias, revela-se! As dimensões entre humano e máquina se diluem e talvez aqui, Roy demonstre com contundência a propaganda da Tyrell Corporation: "Replicantes, mais humanos que os humanos"!

A culminância desse amálgama de emoções, sentimentos, experiências e memórias, na cena final de Blade Runner, não prescinde das pistas que vão sendo construídas ao longo do filme. Esse recurso da memória, sua construção, sua busca e suas narrativas nos fazem humanos e se vinculam diretamente ao desejo de vida, de mais acúmulos de experiências e memórias, também o medo da morte. Esse desejo de vida, expresso já pela criatura de Frankenstein por uma companheira para amar e ser amado, explode com paixão e desejo no diálogo entre Tyrell e sua criatura, Roy. Afirmando que este foi feito da forma mais perfeita possivel, mas retrucado que não foi feito para durar, Tyrell o responde: "A luz que brilha com o dobro da intensidade dura a metade do tempo. E você brilhou com uma enorme intensidade". Mas Roy implora: "quero mais vida... Pai"! (Blade Runner, 1982).

Para Pourriol (2009), amparando-se nas reflexões de Espinosa,10 o desejo de mais vida está ancorado no conatus, no nosso esforço permanente em continuar a ser! A potência de uma coisa/corpo qualquer - seu conatus - sozinha ou em conjunto com outra(s) coisa(s)/ corpo(s) no esforço de fazer qualquer coisa para preservar no seu ser a sua existência, não é outra coisa senão ela mesma, porém, numa versão atualizada (ESPINOSA, 2009). Assim, o que nos identifica como humanos não se deixa nunca fixar, somente deixa-se enunciar. o que distingue uma enunciação de cariz identitário de uma outra é o tipo de intensificação que

10 Espinosa na quarta parte da Ética na proposição 7 menciona que "À natureza de uma substância pertence ao existir" (ESPINOSA, 2009, p. 24). A potência da natureza para esse autor é dupla: "potência absoluta de existir, que se prolonga em potência de produzir todas as coisas; potência absoluta de pensar, portanto de se compreender, que se prolonga em potência de compreender tudo que é produzido" (DELEUZE, 2002, p. 103). 
se agencia pela linguagem. Nesse contexto, a consciência é irrelevante, já que o apetite e o desejo de existir a precedem, tendemos naturalmente à vida, a querer mais vida. Novamente, a criatura de Frankenstein e os replicantes, na figura de Roy, revelam-se plenamente cheios de desejos, apetites e vontades humanas de viver, experimentar, acumular memórias!

A criatura de Frankenstein, no momento em que se perde no mar, chorando abraçada ao corpo inerte de seu criador, enquanto Roy, naquele momento seminal de evocação de lembranças perdidas como lágrimas na chuva, ambos se revelam humanos, porque o vivido não lhes pode ser tirado e aquelas memórias e experiências configuraram suas existências. Prolongando essa interpretação, a identidade humana não está atrelada apenas às imagens de memória, mas à força ou vontade que as produziu: o poder de agir. Vislumbra-se a superação do racionalismo cartesiano para ascender a narrativa segundo uma perspectiva romântica, que na crítica aos iluministas, definiu o humano pelos atos passionais considerados filosófica e cientificamente irracionais; mas plenamente aceitáveis pela potência artística.

Não obstante a tensão entre humano e não humano no limite de suas identidades e memórias está imersa no amplo debate acerca das relações entre história, memória e a constituição das sociedades humanas. Para Le Goff (1990), o conceito de memória hoje pode ser distribuído em distintas áreas disciplinares (Psicologia, Biologia, Neurofisiologia, Psicofisiologia, Antropologia), mas no campo da História se buscou apreender como a memória se consolidou na prática e como conceito, fundindo indivíduo e sociedade. Nesse trajeto, a memória se constituiu e constituiu a humanidade, seja nas sociedades sem escrita, no avanço da escrita, impressão e registro até chegar às raias das memórias eletrônicas e virtuais.
Para Le Goff (1990, p. 498): “O primeiro domínio onde se cristaliza a memória coletiva dos povos sem escrita é aquele que dá um fundamento - aparentemente histórico - à existência das etnias ou das famílias, isto é, dos mitos de origem". A constituição da linguagem escrita em distintas sociedades, a consolidação de práticas comemorativas de rememoração, a consolidação do documento como registro tácito da História, a epopeia da palavra "memória" no Ocidente - dos registros pessoais aos registros administrativos, passando pelos registros financeiros à literatura científica e ficcional - chegamos ao plano da constituição das memórias eletrônicas que estendeu metaforicamente o conceito de memória para todos os níveis posteriores.

A literatura e o cinema, nos últimos dois séculos, tenderam a reproduzir e ressignificar os mitos como fundamento de identidade, seus limites e potencialidades, suas conquistas e tragédias, suas benesses e castigos. No caso de Frankenstein e de Blade Runner, o mito de origem da relação entre criador e criatura, a desobediência, o castigo ou a tragédia estão presentes de maneira inconteste. No mito grego, Prometeu rouba o fogo dos deuses para entregar aos homens. Zeus o condena a uma eternidade preso a um rochedo, tendo seu figado devorado por um abutre de dia e regenerando-se à noite. Na mitologia judaicocristã, Adão é expulso do paraíso após ceder à tentação do demônio e comer do fruto proibido, sendo condenado a uma existência de trabalho, doença, dor e morte. ${ }^{11}$ Se nos mitos

11 Blade runner traz outros signos da sacralidade cristão nesta cena final quando criador e criatura ficam frente a frente. "Ya moribundo, el último y más encarnizado oponente del protagonista, Roy Batty, le perdona la vida y luego expiran, em uma composición de reminiscencias quasi cristológicas, que recorda una Piedad. La analogía está reforzada por otro dato: poco antes se ha atravesado la mano que va perdiendo sensibilidade, con un clavo [...] En el estante de la muerte, deja escapar una paloma que tenía entre sus manos. El hombre-máquina enfrentando al hombre biológico alcanza dimensiones sagradas: concede vida y se ex- 
antigos a afronta ao Criador implica punição da criatura, nos mitos modernos literários e cinematográficos, a ação criadora do homem é punida pela criatura não humana ou não natural: a criatura executa o criador. Primeiramente, o monstro mata Victor Frankenstein e Roy executa Tyrell.

Ambos, o monstro de Frankenstein e Roy Batty, têm longos diálogos com seus "criadores" questionando sua existência, sua identidade, suas memórias. Tais diálogos são expressão do que Le Goff (1990, p. 476) atesta como busca incessante: "A memória é um elemento essencial do que se costuma chamar identidade, individual ou coletiva, cuja busca é uma das atividades fundamentais dos indivíduos e das sociedades de hoje, na febre e na angústia". No limite, o retorno aos mitos de origem está sempre alicerçando nossas dimensões memorialísticas e a busca pelos registros permanentes da memória, nossas identidades. Mas, como se define questão da identidade replicante? Se, no estágio atual de alcance das memórias eletrônicas, expandimos a dimensão do próprio humano podemos inferir que tais limites não podem mais ser postos.

0 registro do passado individual, os alcances do passado coletivo estão em suspeição como dimensões exclusivamente de corpos humanos no filme Blade Runner. Os replicantes, na figura de Roy Batty, expressam que o medo da morte, a experiência da vida, exige uma projeção de futuro. Ao criar "humanos mais que humanos", Tyrell estabeleceu uma ruptura na história. Se existem não humanos com capacidade de registro de memória, de desejos, apetites, de constituição de identidades, estamos no âmbito da descoberta de um Deus (Tyrell) e no limiar das proposições de Espinosa (2009, p. 61-62) acerca do que pode um corpo:

presa de modo oracular, es quien ha visto mas allá de los ojos humanos pueden ver, pero es también quien finalmente acepta la imortalidad (SARTI, 2012, p. 244).
Quanto mais um corpo é capaz, em comparação com outros, de agir simultaneamente sobre um número maior de coisas, ou de padecer simultaneamente de um número maior de coisas, tanto mais sua mente é capaz, em comparação com outras, de perceber, simultaneamente, um número maior de coisas. E quanto mais as ações de um corpo dependem apenas dele próprio, e quanto menos outros corpos cooperam com ele no agir, tanto mais sua mente é capaz de compreender distintamente. É por esses critérios que podemos reconhecer a superioridade de uma mente sobre as outras, bem como compreender por que não temos de nosso corpo senão um conhecimento muito confuso.

A projeção do futuro, a escolha racional pela continuidade da história da humanidade e dos corpos construindo suas histórias estão novamente no embate final entre Deckard e Roy. Podemos compreender que o ato de salvar a vida de Deckard é uma ação prometeica, porque Roy dá à vida criada - a humanidade a possibilidade de emancipação. As ações dos replicantes caminhavam em direção à melhoria da humanidade - primeiro como escravos alienados nas colônias extraplanetárias -, por fim, como sujeitos libertos, emancipados que percebem as infinitas possibilidades da existência não enxergadas pelos "homens livres".

Chegamos, então, ao debate acerca da iminência de uma existência humana ciborgue provocada pelos embates postos em Blade Runner. Na obra original de Philip K. Dick, Do androids dream of electric sheep?, publicada em 1968, o autor se refere às personagens criadas para colonização extraplanetária de androides: "Capaz de funcionar em um mundo alienígena, o robô humanóide - estritamente falando, o andróide orgânico - transformarase na besta de carga móvel do programa de colonização" (Dick, 2002, p. 12). Na etimologia da palavra "Androide", encontramos que andro+eidos (homem + aparência), ou seja, algo que aparenta, sem ser homem. 
Por sua vez, Ridley Scott e os roteiristas Hampton Fancher e David Peoples usaram, em Blade Runner, a expressão "replicante", em vez de "androide".12 Em sua etimologia, "réplica" vem do latim re+plicare, ou reproduzir, copiar, imitar. 0 replicante está para além de o androide, de a imitação sem ser. 0 replicante é uma cópia, daí a problemática de sua existência! Por outro lado, o termo "replicante" também tem sentido de rebelde; de algum implicado em uma causa em termos de contradição. A réplica empírica, portanto, desde Platão, sempre contradiz o ideal originário; a experiência tende a negar a teoria.

Geralmente o ciborgue é compreendido como um corpo humano de partes orgânicas e próteses maquínicas. No campo das narrativas audiovisuais do cinema e da TV, segundo Santaella (2003), desde O Homem de Seis Milhões de Dólares (Kenneth Johnson, Estados Unidos, 1973-1978) e Mulher Biônica (Kenneth Johnson, Estados Unidos, 1976-1978), passando pelo Robocop, o policial do futuro (Paul Verhoeven, Estados Unidos, 1987) até $O$ exterminador do futuro 2 (James Cameron, Estados Unidos, 1992), agregando-se a esta interpretação de Blade Runner, nos permite inferir que os avanços da tecnologia em relação à nossa intervenção na natureza têm nublado, ou mesmo rompido, as fronteiras entre biológico, tecnológico, natural, artificial, humano e pós-humano. Após esse trajeto e as reflexões suscitadas por Blade Runner, podemos deduzir que nos encaminhamos para a perda de fronteiras, para a constru-

12 No Brasil, o conto foi publicado primeiramente como "Androides sonham com carneiros elétricos?", mas desde o sucesso do filme, o conto passou a ser reeditado como "Blade Runner, o caçador de androides", finalmente somente como "O caçador de androides". O fato do filme não usar a palavra androide e ter sido este o subtítulo nacional se deve a dois aspectos: androide é uma palavra mais acessível ao gosto popular que replicante, além de que "caçador" foi uma tentativa de surfar na onda do sucesso da personagem Indiana Jones, em Caçadores da arca perdida e vincular as imagens aventureiras de Harrison Ford ao novo personagem, o "caçador" Deckard. ção de uma nova humanidade ciborgue, afinal, o paradigma do "ciborgue só faz sentido para, em um mundo que exige claras divisões e que busca a pureza, significar a inanidade das próprias categorias a partir das quais o analisam e o instituem" (HOQUET, 2019, p. 48).

Nesse contexto, Yuval Harari (2017) refuta a leitura convencional de que o mito de Frankenstein é um alerta de que não devemos brincar de Deus e criar a vida, ao qual acrescentamos as questões acerca da identidade e da memória em Blade Runner. Para o historiador israelense, o ritmo do desenvolvimento tecnológico está marcando a substituição do homo sapiens por seres distintos, tanto biológica quanto psíquica e emocionalmente. Nesse movimento, podemos colocar em suspeição o próprio termo "humano". Já Donna Haraway (2009), tomando as percepções dos socialistas e feministas, defende o fim das fronteiras entre organismos e máquinas. Para ela, devemos aprender a conviver como ciborgues, porque

neste nosso tempo, um tempo mítico, somos todos quimeras, híbridos - teóricos e fabricados - de máquina e organismo; somos, em suma, ciborgues. O ciborgue é nossa ontologia; ele determina nossa política. O ciborgue é uma imagem condensada tanto da imaginação quanto da realidade material: esses dois centros, conjugados, estruturam qualquer possibilidade de transformação histórica (HARAWAY, 2009, p. 39).

Com isso, é preciso talvez superar o conceito de natureza, de natural, de criado de fora, para uma dimensão na qual tudo é cultural, tudo é humano e artificial por si mesmo. Se a natureza fosse vista sob essa perspectiva, a ontologia humana abarcaria o devir humano não a partir de um modelo de corpo pronto/ dado, logo, concluído; uma vez que ele seria sempre o resultado de construções e desconstruções diante de sua historicidade. A natureza vista sob a perspectiva de Espinosa não separa absolutamente o natural do artificial, pois para ele "o artificio faz parte completamente da na- 
tureza, já que toda coisa, no plano imanente da natureza, define-se pelos agenciamentos de movimento e de afetos nos quais ela entra, quer esses agenciamentos sejam artificiais ou naturais" (DELEUZE, 2002, p. 129).

A imagem do ciborgue - da criatura, do androide, do replicante - pode sugerir uma superação dos dualismos que temos usado para explicar de modo esquemático nossa existência. Uma humanidade ciborgue é buscar a humanidade nos limites de nossa existência terrena, não transcendente, buscar se situar como defende Haraway (2009, p. 99): "prefiro ser uma ciborgue que uma deusa". Enfim, o gesto salvador de Roy e seu discurso acerca de suas memórias e experiências o fazem humano ou um "humano mais que humano"?

\section{Considerações finais ou uma humanidade ciborgue?}

Retomando o objetivo do texto de interpelar a memória para discorrer sobre a dicotomia humano/máquina a partir da narrativa filmica de Blade Runner: o caçador de androide, podemos deduzir que nos encaminhamos para a perda de fronteiras do que caracteriza nossa condição existencial, o diretor Ridley Scott lança nossa ontologia naturalista tradicional ao abismo. A mímesis como metáfora de um super-humano se traduz na própria diegese filmica, provocando um permanente estado de desconforto e inquietação acerca da própria condição humana e dos destinos da humanidade, cujos dilemas são levantados no eixo passado/presente/futuro, de tal modo que seus elos são marcados por opacidades, sombras e cortes. Ridley Scott, a partir de Philip K. Dick, nos provoca: seria um convite para a construção de uma nova humanidade ciborgue? Os ciborgues de Blade Runner ameaçam nossa condição de humanos não por seu poder de exterminação, mas pela identidade com a ontologia metafísica já constituída como "pura" na relação do corpo humano com a técnica desde Prometeu. A metafísica era/é o ramo da filosofia escolástica que buscava conhecer as propriedades lógicas gerais pertencentes a todos os seres.

"A metafísica estuda o ser em geral, o que inclui a natureza da sua existência e sua posição (ou estatuto) na estrutura categorial da realidade" (SANTOS, 2009, p. 36). A ontologia tradicional encerra o humano na noção clássica de natureza sempre fixa, bloqueando o acesso a problemáticas filosóficas do ser inevitavelmente sujeito e indeterminado às dinâmicas de seu contexto/historicidade. O ser humano, preso a essa ontologia, possui no seu âmago a ideia de que esse corpo, ao ser modificado pelo uso das tecnologias, fica descaracterizado de sua condição humana, ou seja, ele passa a ser visto como uma entidade "não humana", "trans-humana" - artificial. Por isso, o ciborgue aparece sempre como signo do limite na medida em que borra as fronteiras de um corpo concebido a partir de uma ontologia natural/pura ameaçando o "fim da espécie humana".

Com isso, é preciso talvez superar o conceito de natureza, de natural, de criado de fora, para uma dimensão na qual tudo é cultural, tudo é humano e artificial por isso mesmo. A imagem do ciborgue - da criatura, do androide, do replicante - pode sugerir uma superação dos dualismos que temos usados para explicar de modo esquemático nossa existência. O ciborgue de Blade Runner, sob essa perspectiva pode ser visto como sinônimo de ontologia na medida em que "nos permite repensar o indivíduo ao abandonar todo 'naturalismo' e ao considerar o quanto o indivíduo é indissociavelmente constituído de organismo e de técnica, de natureza e de artificial, sem que possamos determinar o que realça de um e de outro" (HOQUET, 2019, p. 49). 


\section{Referências}

ALVES, Giovanni. Blade Runner, o caçador de androides. In: . Trabalho e Cinema: o mundo do trabalho através do cinema. Londrina: Práxis, 2006. p. 203-218.

AUMONT, Jacques. $\mathbf{O}$ olho interminável: cinema e pintura. Tradução de Eloisa Araújo Ribeiro. São Paulo: Cosac Naify, 2004. (Coleção cinema, teatro e modernidade)

BAUDRILLARD, Jean. 0 sistema dos objetos. Buenos Aires: Século XXI Editores. 1988.

BECK, José Orestes. Esses momentos "não" ficarão perdidos no tempo como lágrimas na chuva. Blade Runner: da pré-produção ao culto. In: DOMINGOS, Charles Sidarta Machado; BECK, José Orestes; QUINSANI, Rafael Hansen. (org.). Os ciclos da história contemporânea: reflexões a partir da relação Cinema-História. Porto Alegre: Fi, 2018. p. 117-132.

BISKIND, Peter. Como a geração sexo-drogas-e -rock'n'roll salvou Hollywood: easy riders, raging bulls. Rio de Janeiro: Intrínseca, 2009.

Blade Runner, o caçador de androides (Blade Runner). Direção: Ridley Scott. Los Angeles, 1982. 1 DVD (117 min.), son., color., legendado. Tradução: Blade Runner.

BORDWELL, David. La narración en el cine de ficción. Barcelona: Paidós, 1996.

DELEUZE, Gilles. Espinosa: filosofia prática. São Paulo: Escuta, 2002.

DESCARTES, René. Discurso do Método. São Paulo: Martins Fontes, 2001.

DICK, Philip Kindred. 0 caçador de Androides. São Paulo: [s.n.], 2002.

ESPINOSA, Baruch. Ética. Belo Horizonte: Autêntica, 2009.

GUIMARÃES, Armando Rui. Mary Shelley: vida e obra. In: ARAÚJO, Alberto Filipe; ALMEIDA, Rogério de.; BECCARI, Marcos. (org.). 0 mito de Frankenstein: imaginário \& educação. São Paulo: FEUSP, 2018. p. 32-70.

HALBWACHS, Maurice. A memória coletiva. São Paulo: Vértice, 1990.

HARARI, Yuval Noah. Sapiens: uma breve história da humanidade. 29. ed. Porto Alegre: L\&PM, 2017.

HARAWAY, Donna. Manifesto ciborgue: ciência, tecnologia e feminismo-socialista no final do século XX. In: SILVA, Tomaz Tadeu da. (org.). Antropologia do ciborgue: as vertigens do pós-humano. 2. ed. Belo Horizonte: Autêntica, 2009. p. 33-118.

HOQUET, Thierry. Filosofia ciborgue: pensar contra os dualismos. São Paulo: Perspectiva, 2019.

LE GOFF, Jacques. História e Memória. Campinas: Unicamp, 1990.

POLLAK, Michael. Memória e identidade social. Estudos Históricos, Rio de Janeiro, v. 5, n. 10, p. 200212, 1992.

POURRIOL, Ollivier. Cinefilô: as mais belas questões da filosofia no cinema. Rio de Janeiro: Zahar, 2009.

SANTAELLA, Lucia. Culturas e artes do pós-humano: da cultura das mídias à cibercultura. São Paulo: Paulus, 2003.

SANTOS, Marcia Patrizio dos. Corpo: um modo de ser divino (uma introdução à metafísica de Espinosa). São Paulo: Annablume, 2009.

SARTI, Graciela. El mito de la vida artificial en la literatura y el cine. Buenos Aires: Editorial de la Facultad de Filosofia y Letras UBA, 2012.

SHELLEY, Mary. Frankenstein ou o moderno Prometeu. São Paulo: Martin Claret, 2018.

Recebido em: 08/04/2020 Revisado em: 03/08/2020 Aprovado em: 05/08/2020 
Hamilcar Silveira Dantas Junior é doutor em Educação pela Universidade Federal da Bahia (UFBA). Professor do Departamento de Educação Física (DEF) e do Programa de Pós-Graduação Interdisciplinar em Cinema (PPGCINE) da Universidade Federal de Sergipe (UFS).E-mail: hamilcarj@bol.com.br

Fabio Zoboli é pós-doutor em Educação do Corpo pela Universidad Nacional de La Plata (UNLP) da Argentina. Doutor em Educação pela Universidade Federal da Bahia (UFBA). Professor do Departamento de Educação Física (DEF) e do Programa de Pós-Graduação em Educação (PPGED) da Universidade Federal de Sergipe (UFS). Membro do grupo de pesquisa Corpo e política. E-mail: zobolito@gmail.com

Renato Izidoro da Silva é pós-doutor em Ciências Ambientais e Sustentabilidade da Amazônia pela Universidade Federal do Amazonas (UFAM). Doutor em Educação pela Universidade Federal da Bahia (UFBA). Professor do Departamento de Educação Física (DEF) e dos Programa de Pós-graduação em Educação (PPGED) e Interdisciplinar em Cinema (PPGCINE) da Universidade Federal de Sergipe (UFS). Coordenador do grupo de pesquisa Corpo e política. E-mail: izidoro.ufs@gmail.com 